\title{
Life Cycle Impact Assessment of Lead-free Solder Considering the Trade-off Relationship between Toxic Impact and Other Impact Categories*
}

\author{
Norihiro Itsubo, Jaesung Noh* and Atsushi Inaba* \\ Research Center for Life Cycle Assessment, National Institute of Advanced Industrial Science and Technology (AIST), \\ 305-8569, Japan
}

Lead-free solder is a focus of increasing international attention, particularly in the wake of various EU directives (ROHS: on the restriction of the use of certain hazardous substances in electrical and electronic equipment). Lead-free solder is anticipated to reduce toxic environmental impact, but it has been pointed out that energy consumption and other related impacts like global warming caused by the production of lead-free solder may be higher than those for conventional solder. It is necessary to consider this trade-off relationship between types of environmental impact. The aim of this study is to conduct trial calculations of impact assessments of typical lead-free solders and a conventional Sn-Pb solder. Impact categories at the local level are regarded as important in the assessment of current materials, such as impacts caused by exposure to hazardous substances. For these impact categories, the resultant environmental impacts can differ greatly, depending on where emissions occur, even for the same degree of environmental burden. Therefore, LIME (Life cycle Impact assessment Method based on Endpoint modeling) was preferentially used, based on domestic background data. Using a conceptualized damage assessment and damage indicator of human health, we concluded that the avoidance of lead is effective even when the increase in other health impacts are taken into account. The reliability of this result was confirmed by the implementation of an uncertainty analysis.

(Received June 3, 2004; Accepted September 22, 2004)

Keywords: life cycle impact assessment, damage assessment, life cycle interpretation, Monte Carlo simulation, disability-adjusted life year

\section{Introduction}

Due to growing awareness of the hazardous properties of lead, both citizens and legislatures are beginning to demand the development of lead-free products. ${ }^{1}$ Since metals in solders used in electrical products carry a high risk of being eluted into the environment if not properly collected after their life cycle, switching conventional solders to lead-free versions is especially important. On the downside, silver and copper, commonly used in lead-free solders, are both precious metals, and the use of tin is also set to increase along with the switch. There is also the possibility that wider application of lead-free solders will be hindered by higher energy consumption due to the higher melting points of the proposed alternative materials.

To allow an efficient switch to lead-free solder, verification based on a comparison of its usefulness and its impediments is essential. Life Cycle Assessment (LCA), a quantitative assessment method for evaluating environmental burdens and the impact of product systems during their life cycles, has potential to become a precise tool for assessment of lead-free solders. However, conventional environmental assessments of product systems by LCA are mostly limited to $\mathrm{CO}_{2}$ emissions and resource consumption. Lead-free solder is not at present correctly evaluated for its effectiveness in avoiding the lead hazard itself, which is its chief characteristic.

Life cycle impact assessment methods are currently classified into two types: the problem-comparison type where integration is effected through mid-point assessments by means of characterization factors; and damage assessment, where integration is made based on calculation results at

*This Paper was Partially Published in J. Japan Inst. Metals 68 (2004) 43-45 category endpoints using damage factors. ${ }^{2,3)}$ Since the former embodies serious challenges, such as too many items needing to be compared, and biological knowledge is not fully included in its integration, the international trend is towards development of the latter method.

Life cycle impact assessment of lead-free solder was carried out so as to compare it with conventional materials. It was based on LIME (Life cycle Impact assessment Method based on Endpoint modeling), ${ }^{4,5)}$ to logically compare environmental impact in several impact categories, such as global warming and toxic impact. This method was developed as part of the LCA National Project of Japan (METI/ NEDO/JEMAI, 1998 2003), ${ }^{6}$ ) and is capable of arriving at impact assessment employing Japanese background data by selecting suitable protocols from major steps of the LCA: characterization, damage assessment, and weighting. For example, this method can include, in the damage assessment, comparison and integration of health damage caused by emissions of carcinogenic substances and infectious diseases caused by global warming. Therefore, it is capable of quantitatively assessing the trade-off relationship between the toxic impacts and resource consumption of lead-free solder and conventional solders.

However, concerning health impact due to exposure to hazardous materials, this method can include carcinogenesis and respiratory organ illnesses, but chronic diseases of the internal organs and cardiovascular disease caused by exposure to heavy metals are currently out of the scope of the assessment. Therefore, in this study, to avoid the apparent zero impact of lead, we provisionally quoted a damage factor of lead from another article.

This study aimed at screening LCIA of conventional solders and lead-free solder, with the purpose of gaining an overall understanding of the environmental impacts of both 
Table 2 Summary of the assessed objects.

\begin{tabular}{|c|c|c|c|c|}
\hline Alloy composition & $\mathrm{Sn} 37 \mathrm{~Pb}$ & Sn9Zn & $\mathrm{Sn} 3 \mathrm{Ag} 0.7 \mathrm{Cu} 5 \mathrm{Bi}$ & $\mathrm{Sn} 0.7 \mathrm{Cu}$ \\
\hline Melting points & $183^{\circ} \mathrm{C}$ & $198^{\circ} \mathrm{C}$ & $217^{\circ} \mathrm{C}$ & $227^{\circ} \mathrm{C}$ \\
\hline Tensile strength (kgf/mm2) & 4.5 & 5.2 & 10.3 & 3.1 \\
\hline Elongation (\%) & 56 & 47 & 20 & 45 \\
\hline Wet-expansion ratio $(\%)$ & 930 & $\triangle$ & $\triangle$ & $71 \triangle$ \\
\hline Price ratio $(\%)$ & 100 & 120 & 250 & 120 \\
\hline
\end{tabular}

materials. The outline is utilized to select environmentloading substances and to identify category endpoints that require preferentially developed damage factors.

Research on the development of the impact assessment method has been actively conducted internationally, and various methods have already been proposed in Europe, where LCIA research is advanced. However, since assessment approaches vary widely depending on methods, the results obtained sometimes differ markedly, even for the same assessed objects and inventory tables. In this study, we explored the sensitivity of LCIA results to the LCIA method used to obtain them.

LCIA results contain uncertainty, since the parameters and models adopted in the LCIA method and LCI tables involve uncertainty. To obtain correct decision-making, the consideration of uncertainty of the result of LCIA is essential. We implemented an uncertainty analysis to check the reliability of the calculated results as a key step in life cycle interpretation.

\section{Scope of This Study}

\subsection{Outline of this study}

Table 1 shows the process of this study, which followed the procedure described in ISO $14040 .{ }^{7)}$ First of all, the goal and scope of this study were established. Secondly, inventory analysis was conducted and followed by impact assessment, interpretation and conclusion. Uncertainty analysis and sensitivity analysis were implemented in life cycle interpre-

Table 1 Main steps adopted in this study.

\begin{tabular}{lc}
\hline \multicolumn{1}{c}{ Main steps of this study } & Remarks \\
\hline 1. Goal and scope definition & $\begin{array}{c}\text { Selection of assessed objects } \\
\text { Definition of system boundary }\end{array}$ \\
\hline 2. Life cycle inventory analysis & NIRE-LCA \\
DEAM
\end{tabular}

tation.

The lead-free solders $\mathrm{Sn} 9 \mathrm{Zn}, \mathrm{Sn} 3 \mathrm{Ag} 0.7 \mathrm{Cu}$, and $\mathrm{Sn} 0.7 \mathrm{Cu}$ were selected as assessment objects whose data can be obtained comparatively easily. A brief description of materials investigated in the study is described in Table $2 .{ }^{8)}$

\subsection{System boundary and inventory analysis}

Since soldering processes vary depending on the type of lead-free solder being used, we set system boundaries only on common processes between mining and solder production. As a result, solders whose melting point is high might be favorably treated, since their environmental impact during soldering operations is not included. $\mathrm{CO}_{2}$ emissions during the soldering process are estimated to be lower than those of the constituent materials production processes; ${ }^{8)}$ for these reasons, we believe that the exclusion of processes other than those of mining through production does not greatly influence outcome. Environmental impacts associated with disposal and transportation between processes are also not included.

The main process is divided into alloy component production and ingot production. Data on the consumption of each component, depending on alloy composition ratio, and on fuel (kerosene) consumption necessary for alloy production, were provided by Hitachi, Ltd. ${ }^{8}$ Inventory data associated with processes up to production of $\mathrm{Pb}, \mathrm{Cu}, \mathrm{Ag}, \mathrm{Zn}$, and $\mathrm{Sn}$ used as alloy components were obtained from the DEAM database installed in TEAM, an LCA software application. Although details of the method of calculating environmental burden could not be confirmed from this database, the data were utilized, on the assumption that they all included processes from mining to electrolytic refining.

\subsection{Impact assessment}

LIME was employed for impact assessment. This method can be divided into three LCIA steps in line with ISO14042: ${ }^{9)}$ characterization, damage assessment and weighting. Characterization focuses on the contributions of assessed objects to the specific impact categories. Eleven types of impact categories such as global warming are taken into account. Damage assessment integrates these various environmental impacts obtained by characterization into potential damage to the four endpoints. It helps us to consider the relationship 


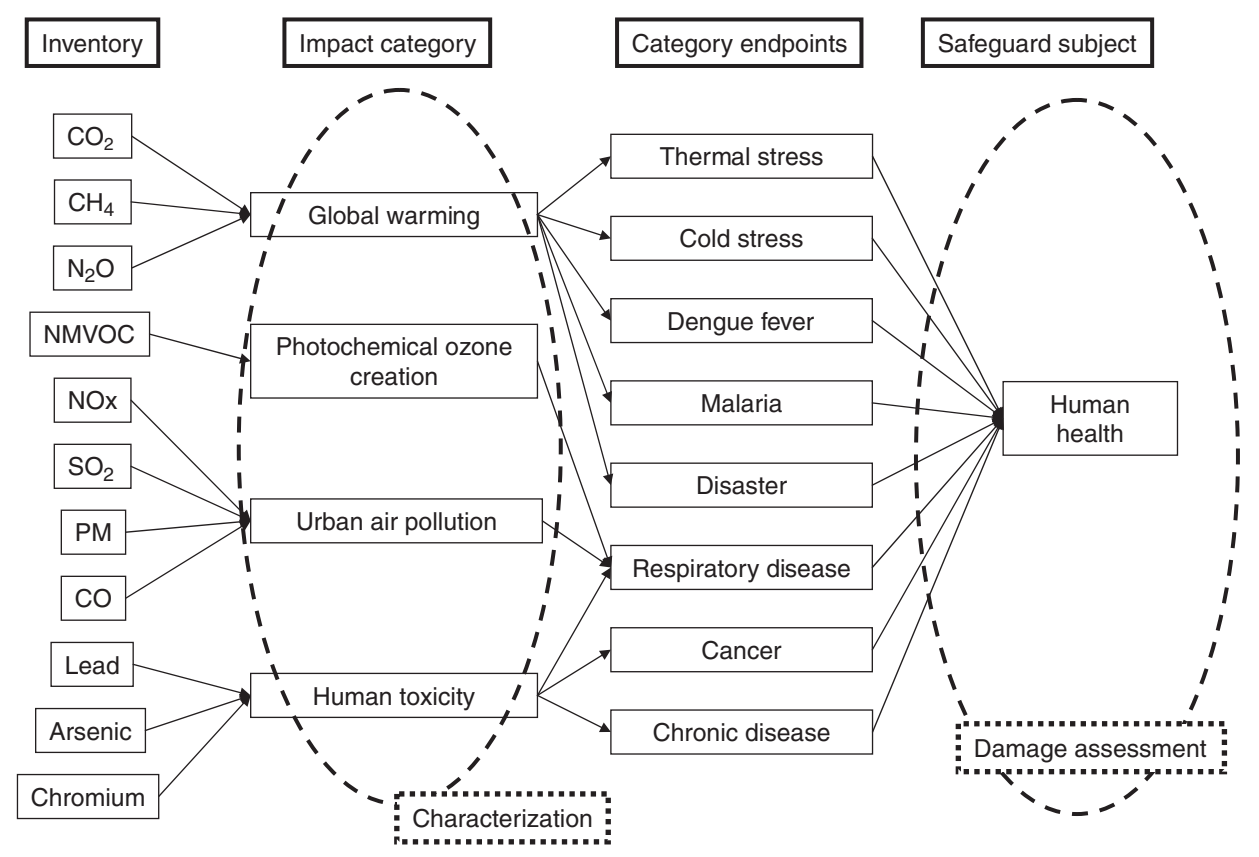

Fig. 1 Scope of LCIA in this study.

between the seriousness of environmental problems through the reduction in the number of quantified items. Weighting is the process of obtaining a single index that takes into account the weighting across the endpoints. This weighting is able to respond to legal imperatives.

In this study, we decided to conduct characterization and damage assessment of health impacts which appear to be highly sensitive to environmental impacts of overall materials, as a result of lead replacement. The damage indicator of the impact on health is expressed in Disability Adjusted Life Years (DALY).

DALY is a health indicator that Murray et al. at Harvard University developed, in a study on Global Burden of Disease (GBD), in cooperation with the World Health Organization at the request of the World Bank. ${ }^{10,11)}$ This research enabled international comparison of burdens of disease (BOD) by gaining a quantitative understanding the BODs of disease by region and by country. It is mainly used in decision-making on health policy and in assigning priorities in dealing with diseases. DALY has greatly contributed to health policy, since it introduced an indicator that is capable of international comparisons and measures both mortality and disorders using a single unit.

DALY is calculated via the following formula, utilizing (1) years of life lost due to premature mortality, (2) social value of years lived (weighted by age), (3) duration discount, and (4) disability weights.

$$
D A L Y s=\int_{x=a}^{x=a+L} D C x \exp (-\beta x) \exp \{-r(x-a)\} d x
$$

where $C x \exp (-\beta x)$ represents weighting by age. $\operatorname{Exp}(-r(x-a))$ shows the duration discount, and $r=0.03$, e.g. $3 \%$ per year, was employed by Murray et al. Life expectancy at the onset of disability or mortality is represented by $a$, and $L$ represents duration of disability or life expectancy at the time of mortality. $D$ is the weighting of disability due to the subject disease; $D=0$ for perfect health and $D=1$ for mortality. The severity of each disease is classified by experts into 7 classes using the Delphi method. It was decided not to employ weighting by age or the duration discount in LIME, and we decided to follow that rule in this study.

Figure 1 summarizes the scope of assessed environmental impacts in this case study. Global warming, ozone layer depletion, air pollution in urban areas, hazardous chemical substances, and photochemical oxidants are included as impact categories contributing to human health damage in the method, and these five categories were on this occasion selected as subjects in the case study. Although LIME can assess impacts, such as air pollution, by distinguishing between local or regional emission locations, it was decided to use damage factors that represent Japan overall. This was obtained from damage factors for each region, since the locations of emissions could not be specified in the current inventory analysis.

The substances included in the current case study and relevant impact categories are listed in Table 3.

Table 3 Impact categories and environmental burden substances included in the assessment in this case study.

\begin{tabular}{ccc}
\hline Impact category & $\begin{array}{c}\text { Destination } \\
\text { of emission }\end{array}$ & $\begin{array}{c}\text { Environmental burden substances } \\
\text { included in the assessment }\end{array}$ \\
\hline Global warming & air & $\mathrm{CO}_{2}, \mathrm{CH}_{4}, \mathrm{~N}_{2} \mathrm{O}, \mathrm{CF}_{4}, \mathrm{Halon} 1301$ \\
\hline $\begin{array}{c}\text { Air pollution in } \\
\text { urban areas }\end{array}$ & air & $\mathrm{PM} 10, \mathrm{SO}_{2}, \mathrm{NOx}$ \\
\hline $\begin{array}{c}\text { Hazardous } \\
\text { chemical } \\
\text { substances }\end{array}$ & $\begin{array}{c}\text { air, water, } \\
\text { soil }\end{array}$ & $\begin{array}{l}\mathrm{Pb}, \mathrm{Be}, \mathrm{As}, \mathrm{Benzene}, \mathrm{Cd}, \mathrm{Cr}(\mathrm{VI}), \mathrm{Ni}, \\
\text { Acetaldehyde }\end{array}$ \\
\hline $\begin{array}{c}\text { Photochemical } \\
\text { oxidants }\end{array}$ & air & NMVOC (37substances) \\
\hline
\end{tabular}


Table 4 Result of selected life cycle inventory of solders (Total: 299 substances)

\begin{tabular}{cccclc}
\hline Substance & Unit & Sn37Pb & Sn9Zn & Sn3Ag0.7Cu & Sn0.7Cu \\
\hline Input & & & & & \\
\hline Coal & $\mathrm{kg}$ & $1.52 \mathrm{E}+0$ & $2.20 \mathrm{E}+0$ & $2.60 \mathrm{E}+0$ & $2.23 \mathrm{E}+0$ \\
\hline Oil & $\mathrm{kg}$ & $9.59 \mathrm{E}-1$ & $1.36 \mathrm{E}+0$ & $1.79 \mathrm{E}+0$ & $1.46 \mathrm{E}+0$ \\
\hline Tin & $\mathrm{kg}$ & $6.30 \mathrm{E}-1$ & $9.10 \mathrm{E}-1$ & $9.63 \mathrm{E}-1$ & $9.93 \mathrm{E}-1$ \\
\hline Output & & & & & \\
\hline Arsenic & $\mathrm{kg}$ & $5.55 \mathrm{E}-2$ & $9.05 \mathrm{E}-3$ & $1.68 \mathrm{E}-6$ & $1.30 \mathrm{E}-6$ \\
\hline $\mathrm{CO}_{2}$ & $\mathrm{~kg}$ & $9.72 \mathrm{E}+3$ & $1.39 \mathrm{E}+4$ & $1.73 \mathrm{E}+4$ & $1.47 \mathrm{E}+4$ \\
\hline Lead & $\mathrm{kg}$ & $5.92 \mathrm{E}-1$ & $1.67 \mathrm{E}-1$ & $1.21 \mathrm{E}-4$ & $1.12 \mathrm{E}-4$ \\
\hline $\mathrm{NOx}^{2}$ & $\mathrm{~kg}$ & $2.69 \mathrm{E}+1$ & $3.78 \mathrm{E}+1$ & $4.51 \mathrm{E}+1$ & $4.00 \mathrm{E}+1$ \\
\hline $\mathrm{PM}^{2}$ & $\mathrm{~kg}$ & $1.49 \mathrm{E}+1$ & $2.14 \mathrm{E}+1$ & $2.62 \mathrm{E}+1$ & $2.30 \mathrm{E}+1$ \\
\hline $\mathrm{SO}_{2}$ & $\mathrm{~kg}$ & $3.65 \mathrm{E}+1$ & $5.17 \mathrm{E}+1$ & $6.36 \mathrm{E}+1$ & $5.44 \mathrm{E}+1$ \\
\hline $\mathrm{NMVOC}$ & $\mathrm{kg}$ & $6.34 \mathrm{E}+0$ & $8.13 \mathrm{E}+0$ & $7.42 \mathrm{E}+0$ & $7.14 \mathrm{E}+0$ \\
\hline
\end{tabular}

\section{Assessment Results}

\subsection{Inventory analysis}

LCI for 299 substances were investigated using domestic and overseas databases. Table 4 shows the results for the selected substances. Regarding emissions of heavy metals like lead, the results for conventional solder were higher than those for lead-free solders. But except for heavy metals, LCIs of lead-free solder were larger than those of conventional solder. We were able to confirm a trade-off relationship between LCI of lead and that of the other items.

\subsection{Impact assessment}

\subsubsection{Characterization}

Characterization was effected by multiplying the obtained inventory data listed in Table 4 by the corresponding characterization factors of each impact category listed in LIME. ${ }^{6)}$

$$
\text { Category Indicator }{ }_{i}=\sum_{\mathrm{s}}\left(\text { inv }_{\cdot s} \times \mathrm{CF}_{\mathrm{i}, \mathrm{s}}\right)
$$

where Category Indicator is the result of characterization, Inv.s is the inventory data $(\mathrm{kg})$ of the environmental loading substance $\mathbf{s}$, and $\mathrm{CF}_{\mathrm{i}, \mathrm{s}}$ is the characterization factor of substance $\mathbf{s}$ belonging to impact category $\mathbf{i}\left(\mathrm{kg}^{-1}\right)$.

Figure 2 shows the results of characterization of lead-free and conventional solder through the production of one unit of solder. Because the dimensions of the category indicator differ according to impact category, the results are normalized to show the ratio of the calculated results to the maximum value. The toxic impacts incurred by production of conventional solder are greater than those of lead-free solder. This is due to the particularly large impact of lead that is emitted into the atmosphere when alloy components are produced.

On the other hand, potential impacts other than toxic impact, such as global warming and acidification incurred by lead-free solder, were revealed to be greater than those incurred by conventional solder, since energy consumption in lead production is less than that for the other alloy components. As in the result of inventory analysis, we confirmed again that there is a trade-off relationship between impact categories.

\subsubsection{Assessment of damage to human health}

Although impact assessments through global warming and air pollution are made by LIME, this method covers only respiratory diseases and carcinogenesis as the impacts of exposure to hazardous substances. Therefore, LCIA based on only that method is currently regarded as unsubstantiated, since LCIA does not include chronic diseases caused by heavy metal exposure. Consequently, an attempt was made to implement LCIA by quoting heavy metal damage effects, including that of lead, from other literature, ${ }^{12)}$ to avoid deviation from the aim of assessing lead-free solders.

Damage assessment was made by multiplying the obtained inventory data by corresponding damage factors of human health in LIME.

$$
\text { Damage }_{\mathrm{HH}}=\sum_{\mathrm{S}}\left(\text { inv.s } \times \mathrm{DF}_{\mathrm{HH}, \mathrm{S}}\right)
$$

where Damage $_{\mathrm{HH}}$ is the result of the damage assessment of human health (DALYs), $\operatorname{Inv}_{\mathrm{s}}$ is the inventory result $(\mathrm{kg})$ of the environmental loading substance $\mathbf{s}$, and $\mathrm{DF}_{\mathrm{HH}, \mathrm{S}}$ is the damage factor (DALYs/kg). ${ }^{6,13-16)}$

Figure 3 illustrates the results of estimates of health damage incurred by lead-free and conventional solder through the production of one unit of solder. The health damage incurred by the production of conventional solder has up to now been about 1.5 2 times greater than that of lead-free solder, due to the particularly large impact of lead that is emitted into the atmosphere when alloy components are produced. Since the energy required in lead production is less than that for other alloy components, the health damage caused by environment-burdening substances other than lead was greater with lead-free solder than with conventional solder (which contains approximately 40\% lead). This indicates that the effect of the reduction of toxic impact caused by lead replacement was sufficiently greater than the increase in health damage caused by the increased emissions of substances other than lead. As for Sn9Zn, the impact of lead emission was approximately $25 \%$ of the total impact. Zinc concentrate is co-produced with lead concentrate in ore dressing processes. In other words, the lead amount emitted in this process should be allocated to the co-products, lead and zinc. Regarding Sn9Zn, we believe that the health impact of lead has become visible as a result of this allocation treatment.

Fifty-five substances were covered in the damage assessment, and five substances (lead, $\mathrm{CO}_{2}, \mathrm{PM} 10, \mathrm{SO}_{2}$, and $\mathrm{NO}_{x}$ ) were shown to be of particular importance. The silvercontaining lead-free solder showed considerable risk of health damage, even though it contains no lead. Although the alloy comprises only about $3 \%$ silver, $\mathrm{SO}_{2}$ emission by silver was about $1 / 5(11 \mathrm{~g})$ of the $\mathrm{SO}_{2}$ emission $(52 \mathrm{~g}$ ) during the production of tin, which makes up approximately $96 \%$ of the alloy. Since similar trends were observed in $\mathrm{CO}_{2}$ and $\mathrm{NO}_{x}$ emissions, the environmental burden caused by silver through the refining process has a major effect on the overall impact, even for the small amount of silver required. 

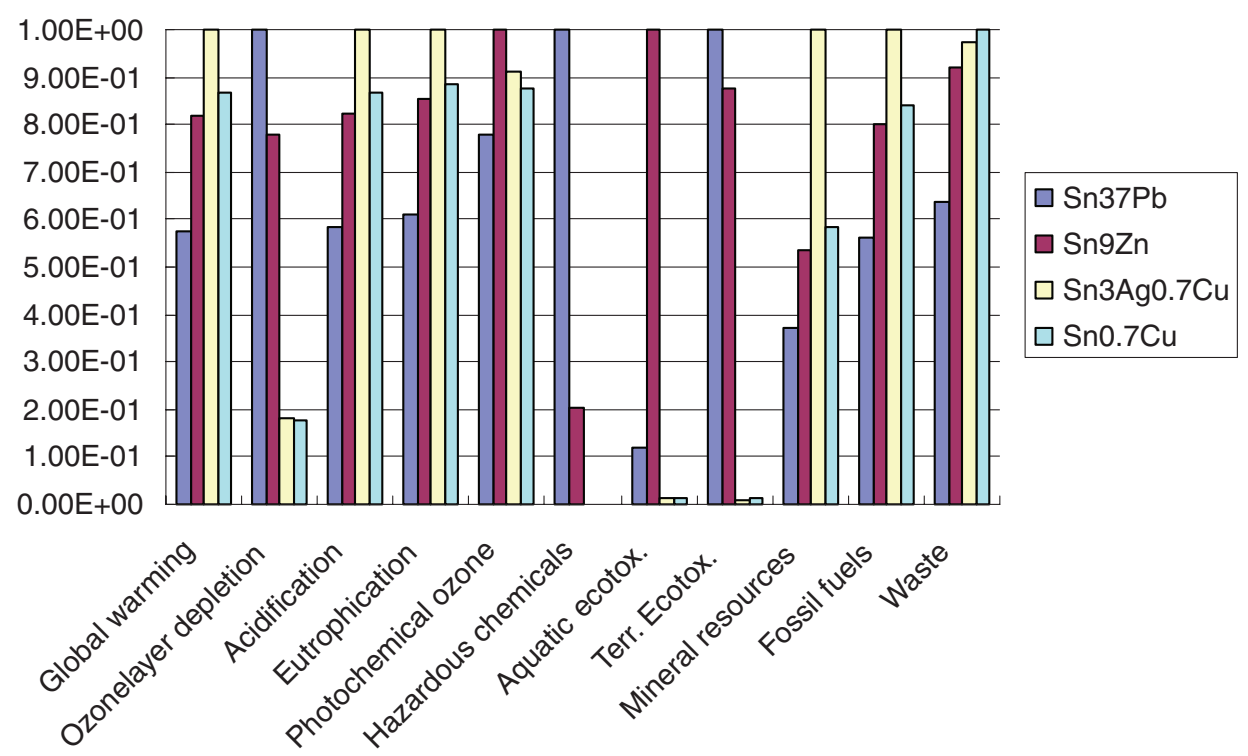

Fig. 2 Result of characterization of solders.

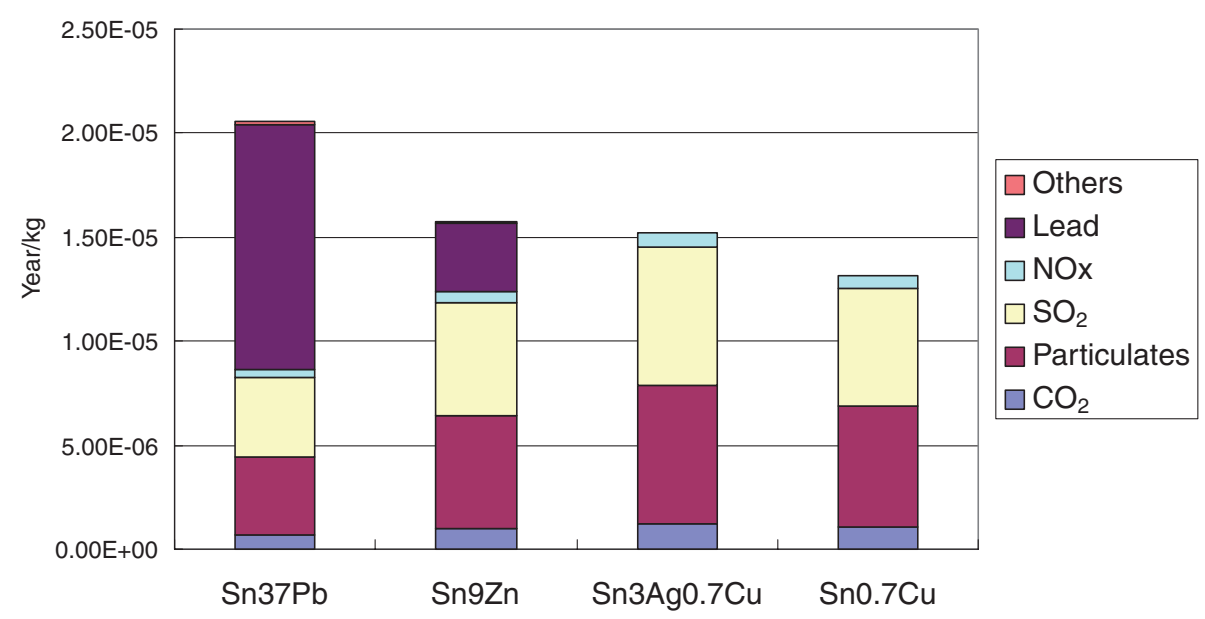

Fig. 3 Result of damage assessment of solders on human health.

\subsection{Interpretation}

\subsubsection{Sensitivity check}

ISO $14043,{ }^{17)}$ which describes the guidelines of life cycle interpretation, requires the implementation of a sensitivity check of the LCIA result. The objective of the sensitivity check is to assess the reliability of the final conclusions by determining whether they are influenced by the selected LCIA methods. Figure 4 shows a comparison of LCIA results using LIME and Eco-indicator 99. ${ }^{18)}$ We can compare the results directly, since the results are shown in terms of the common damage indicator (DALY). These results showed the following numerous similarities, although minor differences can be found.

1. Human impact caused by the production of lead-free solder was smaller than that of conventional solder.

2. Potential damage caused by the emission of lead is very large in spite of the amounts of emission not actually being very great.

3. Respiratory diseases caused by the inhalation of partic- ulates and sulfur dioxide are significant, as are the toxic impacts of heavy metals.

4. The health impact of global warming accounted for less than 20 percent $*$ in overall materials.

\subsubsection{Uncertainty analysis}

To validate the results of LCIA, an uncertainty analysis was implemented taking into account the distribution of damage factors and that of inventory data. Monte Carlo simulation was adopted in the uncertainty analysis. Figure 5 shows the calculated result for the impact by lead-free solder subtracted from that of $\mathrm{Pb}$ solder. Positive values in the horizontal axis indicate that the impact of $\mathrm{Pb}$ solder is higher than that of lead-free solder. The probability that $\mathrm{Pb}$ solder revealed a higher impact exceeded 80 percent. This result is in accordance with the calculated result in Fig. 3. However, the remaining $20 \%$ of the calculated results did not match the results shown in Fig. 5. To improve the reliability of the calculation, the accuracy of the damage factor of lead and inventory data will have to be reconsidered. 


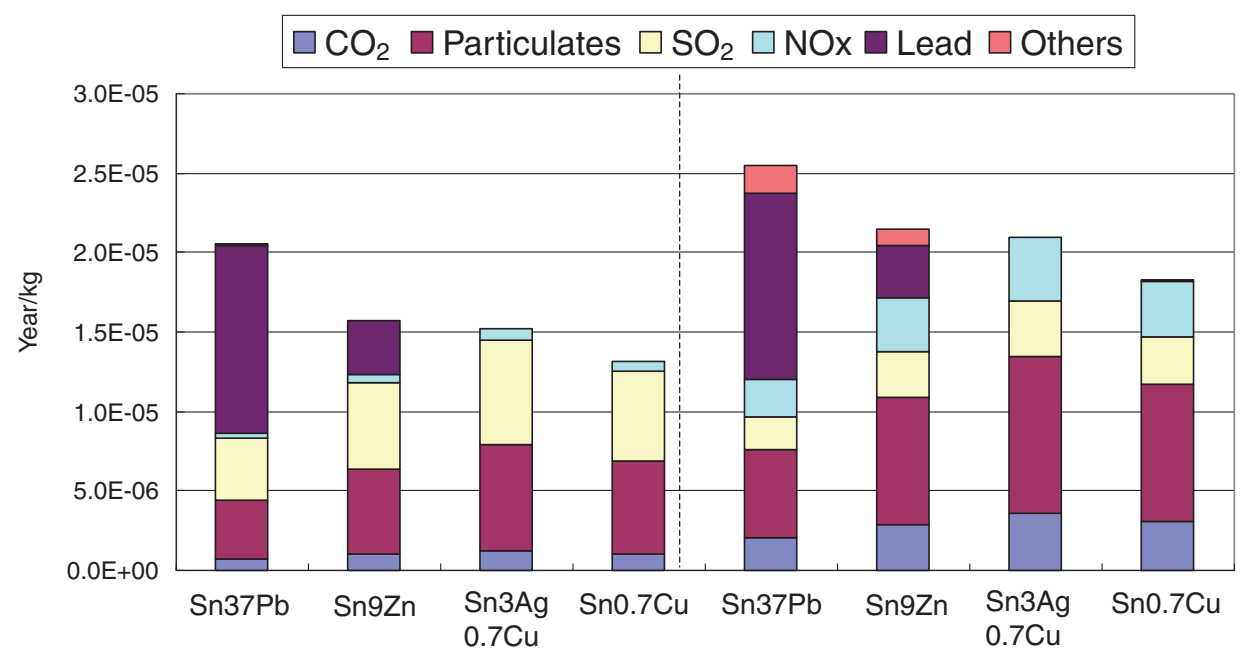

\section{LIME}

Eco-indicator 99

Fig. 4 Result of life cycle interpretation comparing the results applying another LCIA method. Left: the result using LIME; right: the result using Eco-indicator 99.

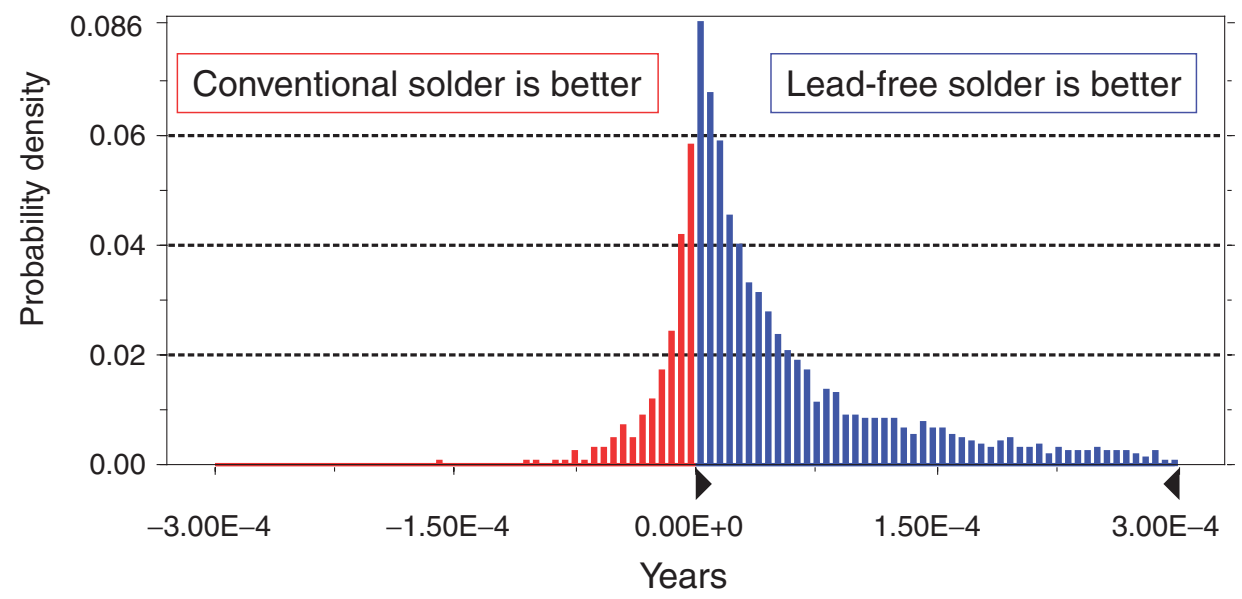

Fig. 5 Result of uncertainty analysis using Monte Carlo simulation; Positive area (blue bars) means that the calculated health impacts caused by conventional solder are estimated to be greater than those of lead-free solder.

\section{Discussion}

The current assessment results estimate that the health damage can be reduced by $40 \sim 50 \%$ by switching from conventional solder (1.8 E-5 DALYs $/ \mathrm{kg}$ ) to lead-free solder (0.9 1.2 E-5 DALYs/kg). Approximately 19,200 tons of conventional solders are currently produced in Japan. Therefore, if all of this were replaced with lead-free solders, it would result in counteracting approximately 150 years of lost life expectancy. Assuming that a willingness to pay (WTP) per YOLL (Years of Life Lost) is Euro 85,000, ${ }^{19)}$ a provisional estimate indicates an avoidance of approximately 1.5 billion Japanese yen in social loss per year. If Japan accounts for $20 \sim 25 \%$ of worldwide solder use, switching to lead-free solders worldwide would lead to a benefit of about JP Yen 6.0 7.5 billion. As described in the survey range, the current results do not include environmental burdening in disposal steps, that is, environmental impact through the scattering and leaking of heavy metals during their crushing, burning, and landfill; these are outside the scope of the assessment. If solders in end-of-life products are not properly collected, and are instead haphazardly emitted into the environment, a greater amount of heavy metals will be emitted into the environment than the amount emitted in the current lead production process $(0.6 \mathrm{~g}$ is emitted into air per $1 \mathrm{~kg}$ of conventional solder manufactured). Therefore, implementation of an inventory analysis that includes reclaiming and recycling is needed.

The $\mathrm{Ag}$ and $\mathrm{Cu}$, and $\mathrm{Pb}$ and $\mathrm{Zn}$ used as alloy components for conventional and lead-free solders are co-produced in the same processes, and therefore allocations of their environmental burdening are required. Sensitivity analyses for different allocation treatments cannot be conducted, since the allocation rules are not described in the inventory database used in the current study. Generally, the ratio of environmental burdening varies greatly for precious metals such as silver, depending on the allocation method. Conclusions could be different among lead-free solders, depend- 
ing on the setting of the allocation method, since the contribution by silver was comparatively large among the assessed objects in the current study.

\section{Conclusions and Future Perspectives}

Data collection required to obtain damage factors for lead as well as the screening of LCIAs was conducted on solders to clarify which items were significant.

DALY is utilized as a damage indicator describing human health damage in LIME. Therefore, parameters are obtained for converting an increment in the number of patients expressed as a damage amount for the category endpoint into the lost of life expectancy, after which health damage factors for heavy metals including lead were calculated.

Provisional calculations of impact assessments were made of typical lead-free solders $(\mathrm{Sn} 37 \mathrm{~Pb}, \mathrm{Sn} 3 \mathrm{Ag} 0.7 \mathrm{Cu}$, and $\mathrm{Sn} 0.7 \mathrm{Cu}$ ) and of conventional solder. The contribution of lead to impact on the environment due to the alloy production process was estimated to be quite large even if its emissions were small (lead emission by conventional solder was $0.6 \mathrm{~g}$ / $\mathrm{kg}$ of solder in this study), according to these results; the effect of lead replacement was thus deemed to be significant.

Although it is desirable to use databases in Japan as much as possible, because emissions including pollutants can possibly vary significantly depending on environmental policies and facilities, overseas inventory data was utilized when domestic data were not available. Although it was decided basically to use LIME in the LCIA, other literature collections were utilized for the environmental impacts not included in the method, particularly chronic diseases caused by long-term exposure to heavy metals. The lead damage factors which were judged important in this case study of the human health damage estimation were quoted from European research results, and therefore, both population density and results of the fate analyses were different from those in Japan. Consequently, damage factors for heavy metals need to be newly developed; these were regarded as important in the current assessment to improve the reliability of the current survey research. In addition to the development of the coefficients, damage estimations between other endpoints like biodiversity and vegetation are needed, along with weighting if trade-offs among safeguard subjects are incurred.

\section{Acknowledgements}

This study was conducted as a part of IMS project
EFSOT, ${ }^{20)}$ "Next Generation Environment-Friendly Soldering Technology". The authors would like to thank Mr. (initial) Serizawa and Mr. (initial) Okamoto (give positions) at Hitachi Ltd. for their support.

\section{REFERENCES}

1) The Parliament and of the Council of the European Union: Official Journal of the European Union 37 (2003) 19-22.

2) N. Itsubo and A. Inaba: Mater. Trans. 44 (2003) 167-172.

3) N. Itsubo and A. Inaba: J. Japan Inst. Metals 66 (2002) 499-505.

4) N. Itsubo and A. Inaba: Int. J. LCA 8 (2003) 305.

5) N. Itsubo, M. Sakagami, T. Washida, K. Kokubu, A. Inaba: Int. J. LCA 9 (2004) 196-205.

6) NEDO, JEMAI: Development of Assessment Technology of Life Cycle Environmental Impact of Product and so forth (2003) 719-912.

7) International Organization for Standardization: ISO14040, Environmental management -Life Cycle Assessment- (1997) pp. 1-10.

8) Hitachi: Collection of LCA data for manufacturing and forming (2000) pp. $1-40$.

9) International Organization for Standardization: ISO14042, Environmental management -Life cycle assessment- Life cycle impact assessment (2000) pp. 1-10.

10) C. Murray: Quantifying the Burden of Disease: the Technical Basis for Disability Adjusted Life Years, Bulletin of the World Health Organization 72 (3) (1994) 429-445.

11) C. Murray and A. Lopez (Eds.): The Global Burden of Disease, Volume 1, WHO/Harvard School of Public Health/World Bank, Harvard University Press, Boston (1996) pp.

12) P. Crettaz: From Toxic Release to Damages on Human Health: A Method for Life Cycle Impact Assessment, with a case study on domestic rainwater use (2000) pp. 134-149.

13) N. Itsubo and A. Inaba: Proc. 4th Int. Conf. on EcoBalance, (2000) pp. 221-224.

14) A. Inaba and N. Itsubo: Proc. 5th Int. Conf. on EcoBalance, (2002) pp. 27-28.

15) K. Itaoka, H. Uchida, N. Itsubo and A. Inaba: Proc. 5th Int. Conf. on EcoBlance, (2002) pp. 37-40.

16) Y. Nagata, T. Ohara, N. Itsubo and A. Inaba: Proc. 5th Int. Conf. on EcoBlance, (2002) pp. 41-44.

17) International Organization for Standardization: ISO14042, Environmental management-Life cycle assessment-Life cycle interpretation (2000) pp. 1-8.

18) M. Goedkoop, R. Spriensma: The Eco-indicator 99, A damage oriented method for Life Cycle Impact Assessment, Methodology Report (1999).

19) B. Steen: A Systematic Approach to Environmental Priority Strategies in Product Development (EPS). Version 2000- Models and Data of the Default Method, Chalmers University of Technology (1999).

20) International Manufacturing System: EFSOT: Next Generation Environment-Friendly Soldering Technology, an IMS project with participation of Japan, Korea and European Union (2001) pp. 1-8. 